\section{Palobra}

ACCESO $\partial$ ABIERTO

Cómo citar: Vergara, C., Méndez, E., \& Navarro, S. (2021). Percepción de calidad y sentido de vida en confinamiento social por la pandemia mundial Covid -19 en estudiantes universitarios. Palobra, 21(1), 117-129. https://doi.org/10.32997/2346-2884-vol.21num.1-2021-3490

Recibido: 13 de enero de 2021

Aprobado: 5 mayo 2021

Editor: Ricardo Chica Gelis. Universidad de Cartagena-Colombia.

Tipología IBN Publindex: Artículo de Investigación Científica.

\title{
Percepción de calidad y sentido de vida en confinamiento social por la pandemia mundial Covid -19 en estudiantes universitarios
}

\section{Perception of quality and meaning of life in social confinement due to the global pandemic Covid-19 in university students}

Cecilia M. Vergara ${ }^{1}$

Universidad del Sinú-Cartagena, Colombia, investpsicologia@unisinucartagena.edu.co Eva M. Méndez ${ }^{2}$

Universidad del Sinú-Cartagena, Colombia, evamendez@unisinu.edu.co

Susana Navarro ${ }^{3}$

Universidad del Sinú-Cartagena, Colombia, susananavarro@ unisinu.edu.co

\section{RESUMEN}

El propósito de esta investigación fue describir la percepción de la calidad y sentido de vida en confinamiento social por la pandemia mundial del Covid-19 de estudiantes universitarios. Se utilizó una metodología cuantitativa, utilizando como instrumentos: una encuesta, un instrumento (WhooQho-Brief) y la escala de sentido de vida PIL. Los hallazgos encontrados permiten identificar que la calidad de vida de vida de los 219 estudiantes se vio medianamente afectada por el confinamiento social en un en un 85\%, reflexionando esta información se analiza que estos estudiantes cuentan con factores protectores como lo son sus relaciones sociales, ayudados a mantener estas relaciones a través de las redes sociales utilizadas, así mismo se puede identificar otro factor protector - la familia -, ya que estos estudiantes en su gran mayoría estaban acompañado por familiares en el momento del confinamiento obligatorio. Así mismo en relación a su sentido de vida podemos identificar que el $49 \%$ manifiesta una alta orientación hacia el logro $(8 \%)$, plenitud (22\%) y realización interior $(19 \%)$; los estudiantes tienen una muy alta percepción del sentido de vida en un 34,7\% asimismo la vivencia del sentido se ubica en un 54,8 $\%$ y la actitud hacia la muerte en un $15,9 \%$.

Palabras clave: Calidad de vida; sentido de vida; confinamiento social; aislamiento; covid-19.

Copyright: (C) 2021. Vergara, C., Méndez, E., \& Navarro, S. Este es un artículo de acceso abierto, distribuido bajo los términos de la licencia https://creativecommons.org/licenses/bync-sa/4.0/ la cual permite el uso sin restricciones, distribución y reproducción en cualquier medio, siempre y cuando que el original, el autor y la fuente sean acreditados.

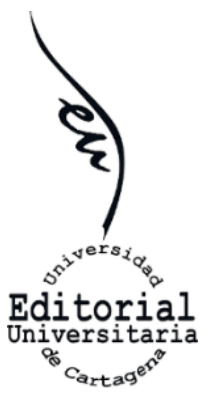

\begin{abstract}
The purpose of this investigation was to describe the perception of the quality and sense of life under a social lockdown on university students due of the Covid-19 pandemic. A quantitative methodology was implemented, using as instruments: a survey, an instrument (WhooQho-Brief) and the PIL sense of life scale. The findings allow us to identify that the quality of life of the 219 students was moderately

\footnotetext{
${ }^{1}$ Líder del Proyecto. Docente, Investigadora de UniSinú Cartagena. Psicóloga, Especialista en Psicología Jurídica.

${ }^{2}$ Co investigadora del Proyecto. Docente, Investigadora de UniSinú Cartagena. Psicóloga, Magíster en Psicología Clínica.

${ }^{3}$ Co investigadora del Proyecto. Docente, Investigadora de UniSinú Cartagena. Psicóloga, Especialista en Psicología Clínica.
} 
affected by social confinement in about $85 \%$ of the student population, finding that many of these students have protective factors such as their social relationships, helping them to maintain live these relationships by the use of social networks tools, likewise another protective factor identified was the family union since these students were mostly accompanied by relatives at the time of mandatory lockdown. Likewise, in relation to their sense of life, we can identify that $49 \%$ manifest a high orientation towards achievement (8\%), fulfillment (22\%) and inner fulfillment (19\%); $34.7 \%$ of the students have a very high perception of the meaning of life, alike the experience of the meaning is located in a $54.8 \%$ and the attitude towards death in a $15.9 \%$

Keywords: Quality of life; meaning of life; social confinement; isolation; covid-19.

\section{Introducción}

El ser humano es un ser social por naturaleza, el cual está acostumbrado y hace parte de su cotidianidad, saludar de mano, de beso, abrazarse, dialogar, reunirse e interactuar con sus familiares, vecinos, compañeros de trabajo de manera presencial y próxima; en donde se establecen normas sociales y de convivencia social, las cuales son aceptadas por las personas. En algunas circunstancias el ser humano se ve obligado a resguardarse en su casa ya sea por catástrofes naturales, accidentes o situaciones de salud, por lo general para mejorar dicha situación; pero surgen situaciones de fuerza mayor en donde nos vemos obligados a aislarnos para contener enfermedades o virus parcialmente desconocidos, mientras se intenta controlar el contagio. El 11 de marzo de 2020, la OMS expide que la propagación del virus por coronavirus puede generar enfermedad del SRAS (síndrome respiratorio agudo severo) y por lo tanto fue declarada como pandemia mundial por Covid-19; en donde los seres humanos direccionados por sus gobiernos deberán por lo regular estar confinados en casa para controlar el contagio y la propagación de dicho virus. Este virus según información de la OMS se inicia en Wuhan (China) en diciembre de 2019, se expande Europa a finales de febrero y llega en marzo al continente americano; este denominado coronavirus hace parte de un grupo de virus que pueden generar enfermedades en animales y en seres humanos; en las personas se conoce que puede causar enfermedades que pueden ir desde un resfriado hasta infecciones respiratorias graves. Los síntomas conocidos más habituales son: tos seca, fiebre y cansancio; también existen síntomas como dolores, congestión nasal, dolor de cabeza, conjuntivitis, dolor de garganta, diarrea, pérdida del gusto y del olfato erupciones cutáneas, cambios de color en dedos de pies y manos. estos síntomas pueden ser leves incluso pasar desapercibidos pero en otras personas tienen consecuencias fatales para la salud tales como dificultad para respirar, dificultad para hablar y moverse, opresión en el pecho, que necesitarán recurrir a atención médica inmediata y a veces hospitalaria; la OMS manifiesta que las personas que tengan afecciones médicas previas como diabetes, cáncer, hipertensión, obesidad, problemas cardiacos o pulmonares podrán tener más probabilidad de llegar a cuadros graves y fatales. 
La OMS nos dice que el virus se propaga de persona a persona por medio de las gotitas que salen de la nariz, boca de las personas infectadas al estas toser o estornudar; por lo tanto esta situación lleva entonces a tomar medidas ante la pandemia mundial, las recomendadas son: lavarse las manos constantemente con agua y jabón, y mantenerse a distancia de hasta dos metros, por lo tanto se recomienda el aislamiento social dado que aún no se tiene el tratamiento exclusivo ni la vacuna para esta enfermedad. El lavado de manos podría conllevar a diversidad de dermatitis en la piel de las personas, las cuales deberán en su momento recurrir al especialista; así mismo el miedo a ser contagiado, el sufrimiento ante la pérdida de algún familiar por el virus, la perplejidad y el aislamiento social por su parte, también podrá traer consecuencias emocionales en los seres humanos, los cuales buscarán también un especialista para tratar el estado emocional en que se encuentren. Este último fue el problema de investigación de este estudio y lo que interesó a las investigadoras; consecuencias a razón del aislamiento social y confinamiento para la no propagación del virus relacionado con la calidad de vida y sentido de vida en medio de la pandemia mundial por Covid-19.

Fue interesante confirmar que esta no ha sido la única pandemia y confinamiento social que se ha dado en el mundo, según historiadores como Borja de Riquer, en Europa ya había pasado por situaciones similares como la famosa gripe española en 1918 donde cobró de 50 a 100 millones de víctimas; esta pandemia tuvo tres olas de contagio; en Madrid se negaron a cancelar las fiestas de San Isidro, los centros educativos y mercados y en menos de 3 meses murieron 10.000 personas y solo el confinamiento social fue la respuesta más efectiva. Otra pandemia fue el azote del cólera en el siglo XIX donde Mallorca, la isla, soportó 28 acordonamientos entre 1789 y 1899, miembros del ejército organizaron cordones armados humanos en la zona afectada para garantizar el aislamiento; otras enfermedades de impacto fueron el H1N1 y el ébola.

El aislamiento social, entonces, es considerado como una medida importante que toman las personas contagiadas para no propagar el virus; y el confinamiento social es una medida que toman las personas no contagiadas para no contagiarse, quedándose en casa junto a familiares de confianza, tomando medidas sanitarias y de protección contra el virus. Entre esas medidas está no salir de casa, dejar de hacer sus actividades diarias cotidianas, tratando de hacer todo en casa (estudio, trabajo, ejercicio, compras, pagar facturas etc) apoyándose de las tecnologías y del internet que permiten hacer actividades sin tener que salir de casa desde los dispositivos móviles y equipos de cómputo. Investigaciones adelantadas en España explican como el confinamiento puede generar impacto psicológico en las personas que viven confinamiento; la investigadora Balluerka Lasa (2020) en su informe de investigación plantea que " en el confinamiento, los dos factores que más afectan al bienestar físico y psicológico son la pérdida de hábitos y rutinas y el estrés psicosocial, de acuerdo al primer estudio que analiza el impacto psicológico de la cuarentena por Covid-19 en China" (Wang, Pan et al., 2020 en Balluerka y cols 2020); y es precisamente ese bienestar psicológico y esa manera de vivir la vida en el confinamiento es lo que se investigó en este estudio. 
En la Escuela de Psicología de la Universidad del Sinú, los estudiantes han tenido que pasar de la presencialidad de sus estudios a la virtualidad del aprendizaje en la disciplina psicológica; esta situación ha conllevado a cambiar sus rutinas y generar en algunos estudiantes situaciones relacionadas con estrés, ansiedad, depresión, etc. Pudiendo esto crear un impacto en su vida, en su proceso de enseñanza y aprendizaje; pero aún más allá de eso pudiendo impactar de alguna manera u otra en su calidad de vida y sentido de vida propósito de estudio de esta investigación. La pandemia ha tenido repercusiones más allá de las consecuencias físicas y psicológicas; el impacto en la economía de los diferentes países, cierre de ciudades, de vías, de negocios, plantas, sector turístico, parques, colegios, etc; también es una situación que genera consecuencias en las finanzas y la manera de conseguir el sustento para cada casa.

Cartagena de Indias, no está aislada de esta situación; la Cámara de Comercio manifiesta en los resultados de la encuesta aplicada el 25 de abril de 2020 que se calcula que "habrá una pérdida de doscientos sesenta y un mil (261.000) puestos de trabajo, lo que equivale aproximadamente al $60 \%$ del empleo formal de la ciudad, según cifras del mercado laboral calculadas por el DANE para el trimestre octubre diciembre de 2019", esta situación económica también llega a impactar en las casas de los estudiantes, dejando sin acceso a la matrícula para la continuación de sus estudios, así como el acceso a las necesidades básicas para la subsistencia; siendo así las cosas, esta situación puede afectar directa o indirectamente la calidad de vida. Para este estudio, la calidad de vida se contempla desde la OMS en Márquez, Loret, Bernabet y cols (2011) así "La percepción del individuo sobre su posición en la vida dentro del contexto cultural y el sistema de valores en el que vive y con respecto a sus metas, expectativas, normas y preocupaciones" y el sentido de vida se considera como lo plantea De Castro, García, González (2017), quienes, sostienen que, lo que define al hombre en última instancia, es el sentido al cual apuntan sus percepciones, intenciones y acciones; desde la relación que establece consigo mismo y el mundo que lo rodea.

El mundo entero se encuentra en pandemia por el Covid-19, que se descubre en Wuhan China, en diciembre de 2019, tras dejar en Wuhan más de 4.512 muertes y 68.125 contagiados; a finales de febrero llega a Europa y deja más de 3.191.484 contagios y 211.252; en marzo llega al continente americano y a la fecha en América Latina se ha convertido en epicentro de la pandemia con casi 4,5 millones de contagios de los 16,5 millones que hay registrados en todo el mundo. El 11 de marzo la Organización Mundial de la Salud (OMS) da el anuncio de declarar el Covid-19 pandemia mundial. En Colombia a la fecha lleva más de 250.000 enfermos y 8.500 víctimas fatales aproximadamente (números en ascenso). Lo anterior genera miedo, incertidumbre, ansiedad, duelo por las pérdidas y el cambio de vida, de rutina de los seres humanos. A nivel mundial van más de 16,3 millones de personas contagiadas y 650 mil muertes aproximadamente. El mundo a raíz de la pandemia de Covid-19, se encuentra en confinamiento social y franjas de cuarentena más rígidas en algunos países y flexibles en otros dependiendo de las estadísticas de contagios.

Declarada la cuarentena en Cartagena, colegios e instituciones de educación superior frenaron sus clases en la ciudad; en el caso de la Unisinú se clausuraron 
las clases presenciales desde el 16 de marzo de 2020 y se iniciaron clases virtuales desde el 23 de marzo; en una acción rápida, la Universidad del Sinú se dispuso a organizar una estrategia para responder a los estudiantes su promesa de valor de los servicios educativos adquiridos en la matrícula; disponer de las plataformas institucionales, apropiarse de otras para las clases remotas, capacitar al equipo docente y cumplir con la cuarentena pero mantener la razón social de la universidad. Fue así como se empezó el 23 de marzo las clases virtuales y en ellas las situaciones que dan vida a esta idea de investigación. Ante la expectativa y por qué no decirlo del desconocimiento de muchos de la pandemia, virus, confinamiento, pruebas covid etc; surge el miedo en algunos estudiantes de lo desconocido, la ansiedad de qué pasará, cuando acabará, me pasará a mí, a mis familiares; empiezan a surgir los casos lejanos, pero luego cercanos a nuestros vecinos, familiares y surgen emociones de tristeza y desesperanza ante la propagación rápida del virus en Cartagena y las cifras en aumento. El propósito de esta investigación fue: Describir la percepción de la calidad y sentido de vida en confinamiento social por la pandemia mundial covid-19 de estudiantes universitarios. A través de una caracterización psicosocial, identificar la calidad de vida en confinamiento social en estudiantes universitarios y también identificar el sentido de vida en el confinamiento social en estudiantes universitarios.

\section{Metodología}

Para describir las características importantes de las diferentes variables (calidad de vida, sentido de vida y confinamiento social) se usó un análisis cuantitativo de tipo descriptivo ya que el estudio pretende identificar las características de la calidad y sentido de vida en confinamiento social de los estudiantes a través de la medición numérica. Los participantes fueron 219 estudiantes universitarios de la Escuela de Psicología, tomados en un muestreo no probabilístico de carácter intencional, con criterios de inclusión: estudiante de la Escuela de Psicología de la Universidad del Sinú, seccional Cartagena, matriculado en el semestre 20202, que sea mayor de edad, voluntario para participar en la investigación y acepte el consentimiento informado.

Los instrumentos aplicados fueron: una encuesta socioeconómica, el WhooQhoBrief, cuestionario diseñado por la OMS que consta de 26 ítems repartidos en los siguientes dominios de la calidad de vida: dominio de salud física, salud psicológica, relaciones sociales y ambiente; las 26 preguntas están distribuidas de la siguiente manera, dos preguntas globales: una es de calidad de vida general, una más de satisfacción con la salud, y las restantes distribuidas así: siete preguntas para evaluar dominio de salud física, seis de salud psicológica, tres de relaciones sociales y ocho ambientales. El cuestionario es respondido desde una escala global que tiene una puntuación del 1 al 5 . Significado de la vida (propósito, meta o misión), satisfacción por la propia vida y percepción de que la vida merece ser vivida, a partir de una adaptación de la prueba psicológica del propósito de la vida (James Crumbaugh y Leonard Maholick).

El procedimiento usado fue el siguiente: 
Etapa 1- Selección de participantes y creación de instrumentos: la parte operativa de este proyecto inició con la identificación de los participantes, paralelamente la construcción de la encuesta y la evaluación de esta por validación de jueces o expertos.

Etapa 2- Aplicación de instrumentos: en esta etapa se aplicó la encuesta el cuestionario de Whooqho-Brief y la escala sentido de vida.

Etapa 3- Tabulación y plan de análisis: proceso de análisis, tabulación, codificación, se realizará el proceso de análisis cuantitativo y estadístico. Con la ayuda del programa estadístico Spss.

Etapa 4- Resultados, discusión y conclusiones

\section{Resultados}

Este estudio partió del propósito de identificar la percepción de calidad y sentido de vida en confinamiento obligatorio por la pandemia mundial del Covid-19; luego de la aplicación de los instrumentos del estudio, las investigadoras empiezan a reflexionar sobre los hallazgos encontrados en esta investigación; iniciemos por darle respuesta al primer objetivo específico, el cual era realizar la caracterización sociodemográfica y psicosocial desde el confinamiento obligatorio; de esto se puede identificar que la muestra (219 estudiantes) tenía una prevalencia de $83,1 \%$ mujeres estudiantes y un $16,9 \%$ hombres estudiantes; de estos estudiantes $84 \%$ vivían en una zona urbana y $16 \%$ zona rural; el $91 \%$ de las edades de los estudiantes oscilan entre 18 a 25 años, en relación a su estado civil y afectivo un gran porcentaje el $48,4 \%$ es soltero (a) sin novio y otro $42 \%$ con novio (a); así mismo en relación al régimen de salud el $48 \%$ de la muestra pertenece al contributivo y el $37 \%$ al subsidiado, otro grupo representado por el $15 \%$ pertenece al régimen especial de salud.

De los hallazgos relacionados con el confinamiento obligatorio y el covid-19 podemos decir que de los estudiantes participantes de este estudio o algún familiar dio positivo para coronavirus en un $19,2 \%$ y el otro $80,8 \%$ dio negativo; del confinamiento obligatorio como tal podemos decir que acataron totalmente el confinamiento en casa un $74,4 \%$, otro $24,2 \%$ lo acató medianamente y un $2 \%$ no lo acató. De las respuestas emocionales en el confinamiento podemos identificar la ansiedad en un 68,5\% la frustración en un $41 \%$ y el miedo en un $35,6 \%$. La muestra que participó en el estudio manifestó que de los canales de información relacionados con el Covid-19 optan por recurrir a los noticieros en $84 \%$; en relación a las redes sociales en un $80,8 \%$. Por otro lado, en el proceso de adaptación al confinamiento los estudiantes manifiestan que se adaptó normalmente en un $44,7 \%$, otro $27,4 \%$ se adaptó fácilmente y el $14,6 \%$ no se adaptó al confinamiento obligatorio. Cabe resaltar que estos estudiantes estaban acompañados en sus viviendas, en un $53,9 \%$ con dos a cuatro familiares los acompañaron y otro 44,3\% por cinco o más familiares identificando aquí un factor protector en relación al sentido y calidad de vida. Por otro lado, en este estudio también se quiso identificar la percepción de calidad de vida en 
confinamiento social en estudiantes universitarios, de esto podemos deducir los siguientes datos presentados a continuación:

Gráfica 1. Calidad de vida.

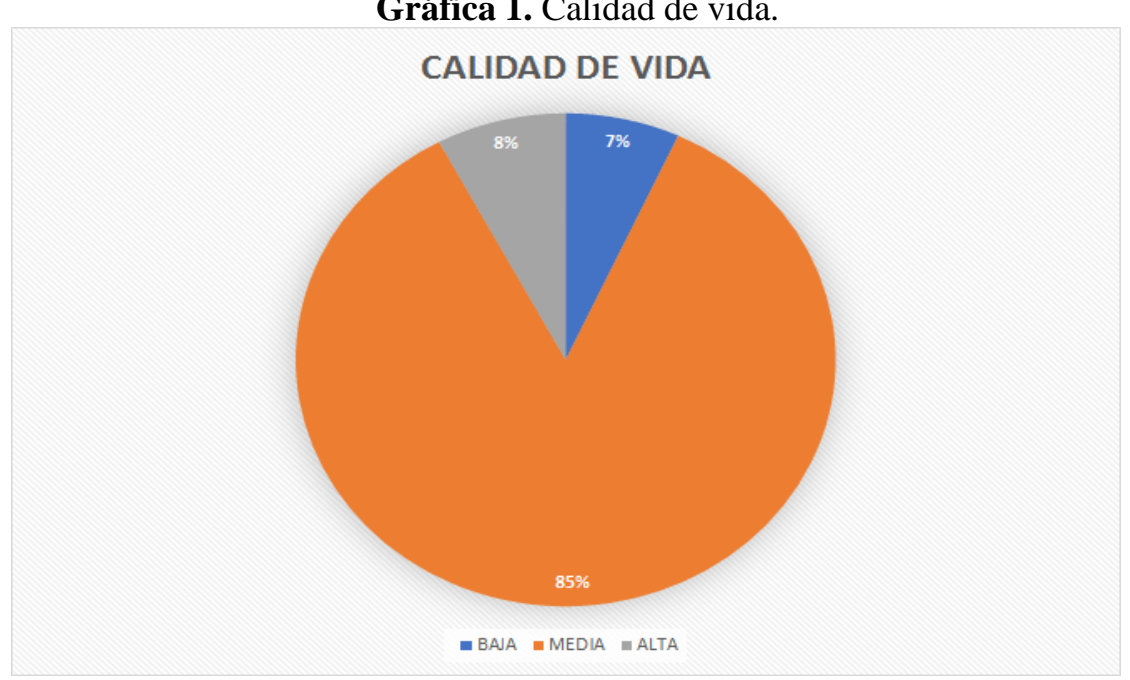

En esta gráfica podemos identificar que en términos globales que la percepción de la calidad de vida y salud de los estudiantes universitarios se ubica en la categoría media en un $85 \%$, otro grupo de estudiantes, representado por el $8 \%$ piensa que es alta y otro representado con el $7 \%$ percibe que es baja.

Gráfica 2. Análisis de la calidad de vida por los dominios.

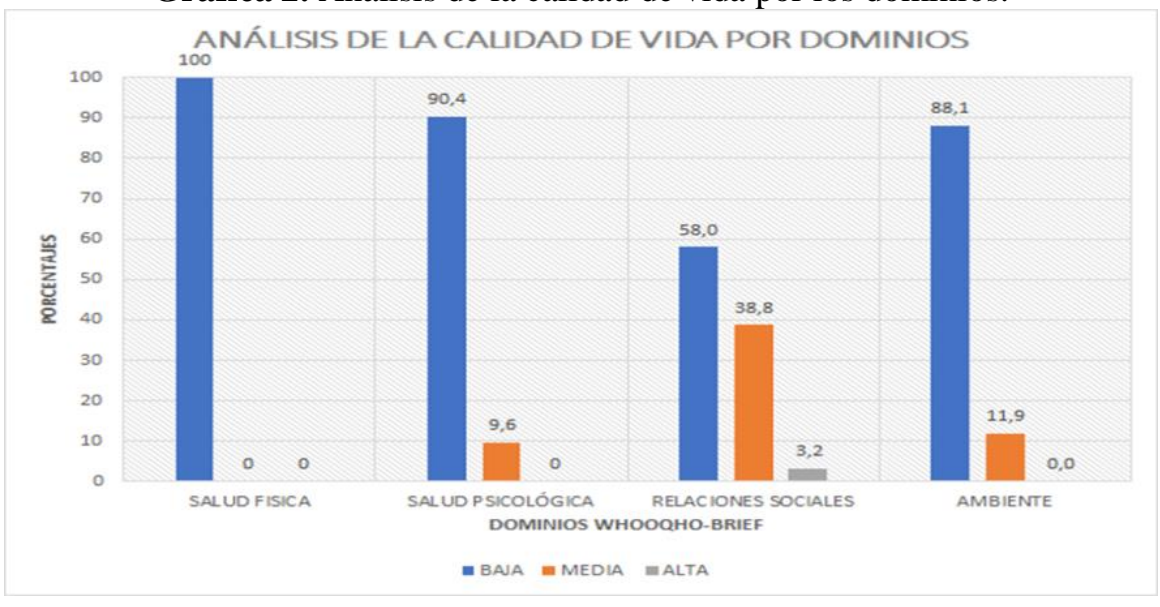

Teniendo en cuenta los datos presentados podemos determinar que en relación a la percepción de la calidad de vida de los estudiantes universitarios en confinamiento social obligatorio por la pandemia, la percepción de su salud física se ubica en una categoría baja, 100\%; en el dominio de la percepción de su salud psicológica se ubica en una categoría baja un 90,4\% y media en un 9,6\%; en el dominio de sus relaciones sociales los estudiantes lo perciben como bajo en un $58,0 \%$, medio en un $38,8 \%$ y alto en un $3,2 \%$; en el último dominio de percepción del ambiente, los estudiantes universitarios consideran que es bajo en un $88,1 \%$ y medio en un $11,9 \%$. 
Identificar el sentido de vida en el confinamiento social en estudiantes universitarios. Permite hacer la identificación de la plenitud del sentido de vida en los estudiantes en un $22 \%$, lo que significa que estas personas encuentran sentido en el diario vivir no sólo en los acontecimientos buenos, sino también en los malos. Por otro lado, se presenta neurosis noógena en un $19 \%$ lo que explica las manifestaciones emocionales propias del aburrimiento y una sensación de vaciedad en su existencia intercalada a la frustración existencial y diversas afecciones somatopsíquicas, lo que soporta la afección del dominio de salud física en el cuestionario de calidad de vida. Se debe tener en cuenta que la neurosis noógena en adolescentes y jóvenes se presenta a través de conductas agresivas, dependencias ( Tv, redes sociales, celular, videojuegos), adicciones, desinterés académico e intención de deserción escolar, falta de esperanza, desdicha, insignificancia e ideación suicida; mientras que en adultos se caracteriza por una sensación de "no poder hallarse", frustración e inconformidad ante la vida y consigo mismo, así como nostalgia de lo que pudo haber sido.

Otro $19 \%$ de estudiantes presentan realización interior, que se representa en la actitud personal que propicia la iniciativa de acción ante situaciones desfavorables. El 16\% presenta el sentido de vida en la zona de frustración o pérdida del interés en descubrir su sentido de vida. Un $11 \%$ cómo lo podemos observar en la gráfica, se ubica en zona de indefinición del sentido, estas personas suelen presentar desmotivación en la realización de sus actividades diarias, la vida puede parecerles rutinaria y monótona, no progresan, ni retroceden-. Una minoría representada en un $8 \%$ se encuentra orientado hacia el logro del sentido, es decir tienen una motivación aceptable y una aceptación de sus compromisos y finalmente, una muestra representada por el $5 \%$ se ubica en un vacío existencial: aburrimiento, indiferencia y apatía.

Gráfica 3. Análisis de sentido de vida




Las investigadoras consideran que es importante analizar los anteriores resultados analizando el grupo etario y pudimos identificar los siguientes datos:

Gráfica 4. Sentido de vida. Comparación por grupo etario

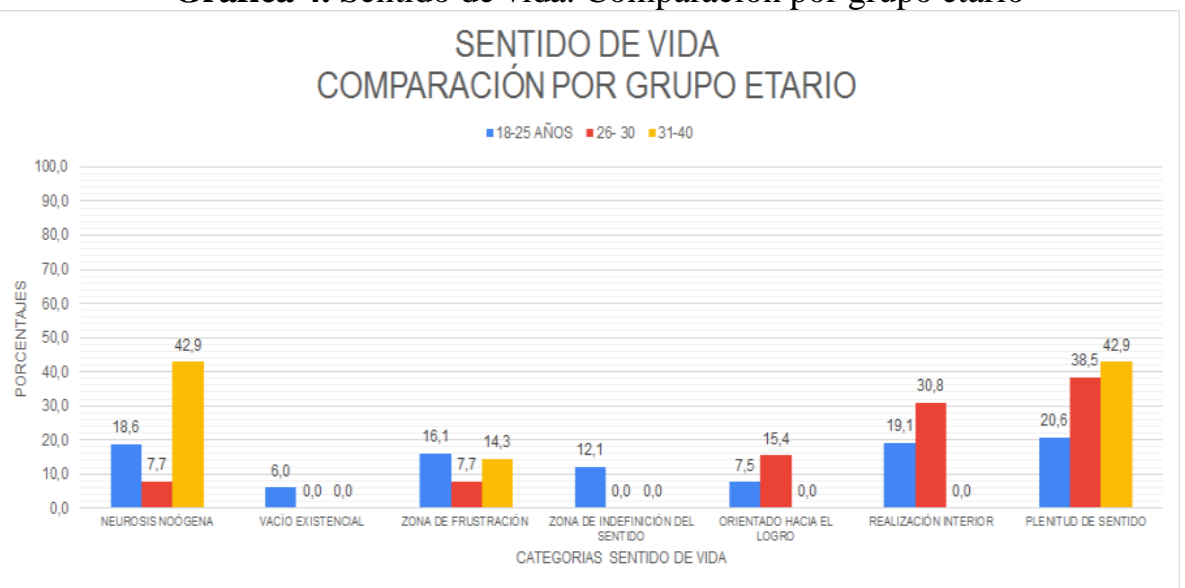

Como podemos observar el grupo de estudiantes que tienen de 31 a 40 años se ubican de manera más radical en las categorías: equilibradamente por un lado un grupo se ubica en la neurosis noógena y el otro, ha desarrollado plenitud de sentido de vida, en un 42,9\% respectivamente en los dos factores. El grupo de estudiantes ubicados en los rangos etarios de 18 a 25 años presenta una distribución más diversa en las distintas categorías, lo cual puede ser explicado por las crisis propias de la adolescencia y adultez joven. Un mayor porcentaje de los estudiantes entre 18-25 años, se encuentran en la zona de frustración 15,1\% en relación a los estudiantes ubicados en los rangos de edades superiores. El grupo de 26 a 30 años, también muestra una variedad en la distribución porcentual con tendencia a las categorías positivas; $15,4 \%$ se siente orientado al logro en relación con los dos grupos, de igual manera se sienten realizados en su interior en un 30,8\% en comparación con los demás.

Finalmente, en relación a los factores (percepción de sentido, vivencia del sentido y actitud hacia la muerte) analizados en la escala de sentido de vida podemos observar los siguientes datos:

Gráfica 5. Resultados por factores




En la gráfica podemos analizar que los estudiantes tienen una muy alta percepción del sentido de vida en un $34,7 \%$, estas personas perciben que por medio de su libertad y responsabilidad que han progresado en su vida. Asimismo, la vivencia del sentido referida a temas vinculados con la vivencia emocional (entusiasmo, placer, satisfacción y novedad vs. al aburrimiento, apatía monotonía) se ubica en un $54,8 \%$ y la actitud hacia la muerte, es muy alta, en un $15,9 \%$, en consideración a las preguntas de haber nacido o no, actitud ante el suicidio y la muerte como destino inevitable.

Por otro lado, presentan muy baja percepción del sentido de vida en un 11,9\%; otro grupo de estudiantes representados por el $10,5 \%$ presentan la vivencia del sentido de vida y un $25,1 \%$ presenta una tendencia de actitud hacia la muerte. Este último sería un indicador a profundizar dada la situación de casos de personas contagiadas, índice de muerte, confinamiento y las respuestas emocionales identificadas de ansiedad, miedo y depresión.

\section{Discusión}

Dados los resultados obtenidos podemos reflexionar que el confinamiento social obligatorio y las medidas tomadas por los estudiantes en Cartagena: no salir de casa, dejar de hacer sus actividades diarias cotidianas, tratando de hacer todo en casa (estudio, trabajo, ejercicio, compras, pagar facturas etc) apoyándose de las tecnologías y del internet que permiten hacer actividades sin tener que salir de casa desde los dispositivos móviles y equipos de cómputo influyó en la percepción de calidad y sentido de vida de los estudiantes sujetos de estudio del presente proyecto de investigación. Coincidimos con la investigadora Balluerka Lasa (2020) cuando en su informe de investigación plantea que "en el confinamiento, los dos factores que más afectan al bienestar físico y psicológico son la pérdida de hábitos y rutinas y el estrés psicosocial, de acuerdo al primer estudio que analiza el impacto psicológico de la cuarentena por Covid-19 en China" (Wang, Pan et al., 2020 en Balluerka y cols 2020); y es precisamente ese bienestar psicológico que permite tener una adecuada percepción en relación a la calidad de vida el que se vio alterado dado que en los estudiantes se encontraba medianamente adecuada, representada por $85 \%$ de estos estudiantes.

Coincidimos también en nuestra revisión teórica con los postulados de De Castro, García, González, (2017) cuando emite que lo que define al hombre en última instancia, es el sentido al cual apuntan sus percepciones, intenciones y acciones; desde la relación que establece consigo mismo y el mundo que lo rodea. Es claro que estas percepciones, intenciones y acciones se desarrollan sobre el marco de la pandemia y el confinamiento social obligatorio vivido en 2020 en Cartagena y en el mundo entero, donde estos determinismos llamados por De Castro y cols, ofrecen una gama de posibilidades y actuaciones, con las cuales se debe resonar afectivamente, con el fin de asumir cada vivencia de cara a la realidad. Los estudiantes construyen y resignifican el sentido de vida a la luz de la realidad actual, Lo que explica la variedad de reacciones en relación al momento de vida específico y la crisis de sentido propiciada por la pandemia actual. Es de anotar sin embargo, que algunos de estos se adaptaron y pudieron entonces establecer 
y desarrollar a pesar de la situación- una plenitud de sentido de vida ( $22 \%$ ) y una realización interior ( 19\%).

El afrontamiento con la muerte, así como situaciones límites en los que se percibe que puede estar en riesgo la vida propia o de una persona allegada, propicia el desarrollo y una evaluación personal sobre cómo se está viviendo. Yalom (2010) sostiene que las personas que se han encontrado de cara a la realidad de la muerte demuestran una reestructuración de las prioridades de la vida; trivialización de lo trivial, expresan un sentido de liberación: bajo la capacidad de elegir solo lo que se desea hacer, un sentido realzado de la vida en el presente inmediato, aprecio por hechos elementales de la existencia, comunicación con las personas amadas más profunda y menos temores interpersonales. Lo que explica que aún bajo la situación de pandemia un gran porcentaje de la muestra manifieste orientación al logro, realización interior y plenitud.

\section{Conclusiones}

A pesar de las reacciones de ansiedad, depresión y miedo, los estudiantes lograron adaptarse al confinamiento obligatorio permitiendo entonces la continuación de sus actividades educativas de forma virtual, sociales a la distancia y relaciones personales por otras vías distintas a la presencial. La pérdida de familiares o conocidos a causa del Covid-19, factores que desencadenan y mantienen las respuestas emocionales de ansiedad y miedo. Las afectaciones en la economía familiar requirieron buscar estrategias de generación de ingreso económico, como lo fue actividades desde casa, búsqueda de empleo por estudiantes que no lo estaban haciendo para apoyar a sus familias.

Las redes sociales y los canales de comunicación permiten a los estudiantes mantenerse informados y en comunicación con sus pares; sin embargo, algunas relaciones se deterioraron por el distanciamiento físico, a pesar de lo anterior esta última sigue siendo uno de los principales factores protectores ante las sensaciones de vacío y pérdida del sentido interior.

Uno de los aspectos a resaltar, en relación al sentido de vida es el papel del afrontamiento a la realidad de la muerte representado en la situación de pandemia Covid-19. La diversidad en los resultados nos muestra que la realidad de la muerte es una experiencia que, aunque por un lado desespera, al mismo tiempo puede propiciar cambios positivos en la resignificación del sentido vital. El focalizar y valorar cada una de las vivencias cotidianas, reconociendo aquellos aspectos esenciales y elementales de la naturaleza humana como: las relaciones sociales, la familia, la salud, la vida misma: que previo a pandemia podían ser consideradas inmutables o "dadas" por sentado-continúan siendo los principales gestores de bienestar, calidad de vida y sentido.

El afrontamiento a la pandemia Covid-19 y sus efectos colaterales, conlleva a su vez a numerosos aprendizajes inter e intrapersonales independientemente de la edad; la reestructuración de la existencia propicia una visión enmarcada en los sentimientos de gratitud, una comunicación más profunda con las personas amadas y una vivencia más consciente de la vida presente, en el aquí y ahora. 


\section{Referencias Bibliográficas}

Apaza P., Cynthia M, \& Seminario Sanz, Roberto Simón, \& Santa-Cruz Arévalo, Johanna Elena (2020). Factores psicosociales durante el confinamiento por el Covid-19 - Perú. Revista Venezolana de Gerencia, 25(90), 402-413. [fecha de Consulta 5 de Agosto de 2020]. ISSN: 1315-9984. Disponible en: https://www.redalyc.org/articulo.oa?id=290/29063559022

Argyle, M. (1993). Psicología y la calidad de vida. Intervención Psicosocial, 2(6), 5 15.

Colegio Colombiano de Psicólogos (2011). Deontología y bioética del ejercicio de la psicología en Colombia. TC Impresores Ltda. Bogotá: Colombia (Pág. 17)

Congreso de Colombia. (21 de enero de 2013). Presidencia de la República. Obtenido de https://www.minsalud.gov.co/sites/rid/Lists/BibliotecaDigital/RIDE/DE/DIJ/ley1616-del-21-de-enero-2013.pdf

De Castro, A., García , G., \& González, R. (2017). Psicología clínica: Fundamentos existenciales ( 3 ed.). Barranquilla: Universidad del Norte.

Espada, José P., \& Orgilés, Mireia, \& Piqueras, José A., \& Morales, Alexandra (2020). Las buenas prácticas en la atención psicológica infanto-juvenil ante el Covid-19. Clínica y Salud, 31(2), 109-113. [fecha de Consulta 5 de Agosto de 2020]. ISSN: 1130-5274. Disponible en: https://www.redalyc.org/articulo.oa?id=1806/180663452007

Frankl, V. (1991). El hombre en búsqueda del sentido. Barcelona: Herder.

Frankl, V. (1994). El hombre doliente. Barcelona: Herder.

Frankl, V. (1994). La voluntad de sentido. Barcelona: Herder.

Fromm, E. (1947). Miedo a la libertad. Barcelona: Paidós

García Martín, M. (2002). El bienestar subjetivo subjective well-being. Departamento de Psicología Social, Málaga, Escritos de Psicología, 6, 18-39

Gianmarco Márquez-Montero Christian Loret de Mola Antonio Bernabé-Ortiz1 Liam Smeeth, Robert H. GilmanJ, Jaime Miranda (2011). Calidad de vida vinculada a salud en población migrante rural-urbana y población urbana en Lima, Perú. Revista Perú Med. Exp. Salud Pública. 2011; 28(1): 35-41

Hernández, R., Fernández. C. \& Baptista. (2014). Metodología de la investigación. México: Mac Graw Hill.

Hurtado, J. (2010). El proyecto de investigación. Caracas: Quirón Ediciones.

Inchausti, Felix, \& García-Poveda, Nancy V., \& Prado-Abril, Javier, \& SánchezReales, Sergio (2020). La psicología clínica ante la pandemia Covid-19 en España. 
Clínica y Salud, 31(2), 105-107. [fecha de Consulta 5 de Agosto de 2020]. ISSN: 1130-5274. Disponible en: https://www.redalyc.org/articulo.oa?id=1806/180663452006

Lawton, M.P. (1983). The varieties of well-being. Experimental Aging Research, 9, 65-72.

May, R. (2000). Amor y voluntad. Barcelona: Gedisa.

May, R. (1988). Libertad y destino en psicoterapia. Biblioteca de Psicología Descleé de Brouwer S.A

May, R. (1963). Bases existenciales de la psicoterapia. Rollo May (Ed). Psicología existencial. Buenos Aires: Paidós.

May, R. (1963). El surgimiento de la psicología existencial. Rollo may (Ed). Psicología existencial. Buenos Aires: Paidós.

May, R. (1983). El hombre en busca de sí mismo. Buenos Aires: Editorial Central.

OMS. (1972). Constitución de la Organización Mundial de la Salud. OMS (Organización Mundial de la Salud).

OMS. Página web oficial de enfermedad de coronavirus: Sitio web sobre la Covid19: https://www.who.int/es/emergencies/diseases/novel-coronavirus-2019

Restrepo Ochoa, D. A., \& Jaramillo Estrada, J. C. (2012). Concepciones de salud mental en el campo de la salud pública.

Rodríguez Gómez G., Gil Flores, J., García Jiménez, E. (1996). Metodología de la investigación. Granada -España: Ediciones Aljibe.

Taylor, S.J., Bogdan, R. (1990). Introducción a los métodos cualitativos de investigación. Barcelona: Paidós.

Tovar, J. G., \& Montaño, A. H. (2012). La desesperanza aprendida y sus predictores en jóvenes: análisis desde el modelo de Beck. Enseñanza e Investigación en Psicología, 17(2), 313-327.

Veenhoven, R. (2001). Calidad de vida y felicidad: no es exactamente lo mismo. Fundación Humanismo y Ciencia, Archivo de la Felicidad. Publicado en italiano en:" G. De Girolamo y col. (eds) "'Qualita' della vita e felicita'"; Centro Scientifico Editore, Torino, Italia pp. 67-95 Traducido al español por Catalina Aguiló, segunda corrección por Vanessa González Aerero. www.fun-humanismociencia.es/felicidad

WHOQOL Group (1993) Study Protocol for the World Health Organization Project to develop a Quality of Life Assessment Instrument (WHOQOL) Qual Life Res, 2: $153-159$

Yalom, I. (1984). Psicoterapia existencial. Barcelona: Herder. 